ORIGINAL RESEARCH

\title{
Tele-education on Leprosy: Evaluation of an Educational Strategy
}

Maurício Pedreira Paixão, M.D., Ph.D., ${ }^{1}$ Hélio Amante Miot, M.D., Ph.D., ${ }^{2}$ and Chao Lung Wen, M.D., Ph.D.'

'Discipline of Telemedicine, Sao Paulo University's School of Medicine, Sao Paulo, Brazil.

${ }^{2}$ Department of Dermatology, Sao Paulo State University (Unesp), Botucatu, Brazil.

\section{Abstract}

The purpose of this research was to evaluate educational strategies applied to a tele-education leprosy course. The curriculum was for members of the Brazilian Family Health Team and was made available through the Sao Paulo Telehealth Portal. The course educational strategy was based on a constructivist learning model where interactivity was emphasized. Authors assessed motivational aspects of the course using the WebMAC Professional tool. Forty-eight healthcare professionals answered the evaluation questionnaire. Adequate internal consistency was achieved (Cronbach's alpha =0.79). More than 95\% of queried items received good evaluations. Multidimensional analysis according to motivational groups of questions (STIMULATING, MEANINGFUL, ORGANIZED, EASY-TO-USE) showed high agreement. According to WebMAC's criteria, it was considered an "awesome course." The teleeducational strategies implemented for leprosy disclosed high motivational scores.

Key words: education, distance, telemedicine, leprosy

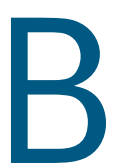
Introduction

razil is the second country in the world in the number of leprosy cases, accounting for more than 50,000 new cases each year. ${ }^{1}$ Many of them are in a region called Legal Amazon, an area in Brazil that occupies more than 5 million square kilometers. The area is characterized by dense forest, rivers, lack of roads, and only minimum infrastructure presenting challenges for the region's inhabitants, especially with respect to healthcare. ${ }^{2}$

Since 1994, Brazil's Health Ministry has created the Program of Family Health Team (FHT) to deal with the primary healthcare. One of its courses of action is the fight against Brazilian endemic diseases, among them leprosy. The FHT is composed of a multiprofessional team including doctors, nurses, and nursing assistants/technicians. The health education strategy focused on continuous instruction to improve the FHT skills.

An increase of over 3,000\% in the number of FHTs was noted from 1996 to 2007. It is important to seek solutions to meet this growing demand, including continuous instruction. ${ }^{3}$ In this scenario, teleeducation may be a suitable solution, providing simultaneous training, wide coverage, and low operational cost. With the emergence of initiatives aimed at health tele-education, it is essential to adhere to evidence-based pedagogic proposals, ${ }^{4}$ which must focus on learning, and to validate them it is necessary to evaluate the foundations systematically and critically.

This work aims to assess the first tele-education course on leprosy directed to FHT emphasizing the motivational aspects of the pedagogic method.

\section{Materials and Methods}

The Discipline of Telemedicine at Sao Paulo University's School of Medicine created and managed a Leprosy Extension University Course as part of the Telehealth Primary Care Project from the Brazilian Ministry of Health. The course was made available through the Sao Paulo Telehealth Portal (http://www.telessaudesp. org.br).

The course was aimed at FHT members and comprised a multiprofessional curriculum on leprosy. Further details on course structure and dynamics were already reported ${ }^{5}$ and are available at http:// www.teses.usp.br.

Tele-educational resources were mediated by professors and coordinators, and included the use of theoretical content available through the Web, discussion lists, ${ }^{6}$ chats, activity diaries, 


\section{Table 1. WebMAC Professional Adapted to the Course}

\section{QUESTIONS}

1. The screen layout of this course is attractive.

STIMULATING

2. There is a menu of site map at the beginning that describes what content is contained within the course.

3. Audiovisual information included in this course helps to clarify or describe the course content.

4. Navigating this course does not require any special skills or experience by me.

5. There is an eye-catching title and/or visual on the home page of this course that will attract participants' attention.

6. This course provides valuable links to other useful references, including Web sites.

7. The purpose of this course is always clear to me.

8. The course has a help function that I can use at any time.

9. This course is fun for participants to explore.

10. The course information is provided by credible sources.

11. The directions for using this course are simple and clear.

12. I can control the pace of moving through this course at all times, including the use of the resources. ${ }^{b}$

13. The content information included in course is interesting.

14. The information contained in this course is current and up-to-date.

15. There is useful information on each topic at the course resources. ${ }^{b}$

16. The course resources ${ }^{b}$ are crisp and clearly visible.

17. The variety of formats used in all resources ${ }^{b}$ helps to maintain attention.

18. The information at this course is accurate and unbiased.

19. All of the information at this course is presented using clear and consistent language and style.

20. All of the course resources ${ }^{b}$ are active and fully functioning.

21. This course has novel or unique features that make it more interesting for participants.

22. There is little or no unimportant or redundant information at this course.

23. The course content is well-written without grammatical, spelling, or other errors.

24. At all times, I can control what information at the course I wish to see.

25. There are unexpected surprises at this course.

26. This course provides opportunities for interactivity to engage students.

27. This course provides the appropriate amount of information on the topic for a lesson or assignment.

28. All resources ${ }^{b}$ and other navigation mechanisms for moving around at this Web site work the way they should.

29. The colors and/or background patterns used in this course are pleasing

30. This Web site provides opportunities to communicate with its authors, participants and technical support.

31. No matter where I am in this course, I can access any resources ${ }^{b}$ and return to the course page or exit.

32. There is enough amount of time to learn how to use the resources. ${ }^{b}$

MEANINGFUL

ORGANIZED

EASY-TO-USE

STIMULATING

MEANINGFUL

ORGANIZED

EASY-TO-USE

STIMULATING

MEANINGFUL

ORGANIZED

EASY-TO-USE

STIMULATING

MEANINGFUL

ORGANIZED

EASY-TO-USE

STIMULATING

MEANINGFUL

ORGANIZED

EASY-TO-USE

STIMULATING

MEANINGFUL

ORGANIZED

EASY-TO-USE

STIMULATING

MEANINGFUL

ORGANIZED

EASY-TO-USE

STIMULATING

MEANINGFUL

ORGANIZED

EASY-TO-USE

Note: The WebMAC questionnaire was adapted with the permission of its authors.

aEvaluated dimension were evaluated, according the level of agreement, as: "3 = Strongly agree," "2 = Somewhat agree," "1 = Somewhat disagree," and "0 = Strongly disagree."

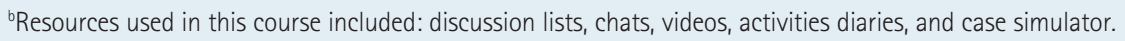


PAIXÃO ET AL.

\section{Table 2. Frequency Distribution of the Answers Obtained by Question $(n=48)$ and Z Scores by Residual Analysis}

\begin{tabular}{|c|c|c|c|c|c|c|c|c|}
\hline \multirow[b]{3}{*}{ QUESTION } & \multicolumn{8}{|c|}{ ANSWER } \\
\hline & \multicolumn{2}{|c|}{ STRONGLY DISAGREE } & \multicolumn{2}{|c|}{ SOMEWHAT DISAGREE } & \multicolumn{2}{|c|}{ SOMEWHAT AGREE } & \multicolumn{2}{|c|}{ STRONGLY AGREE } \\
\hline & FREQUENCY & Z SCORE & FREQUENCY & Z SCORE & FREQUENCY & Z SCORE & FREQUENCY & Z SCORE \\
\hline 1 & 0 & -0.54 & 0 & -0.83 & 5 & -1.41 & 43 & 1.7 \\
\hline 2 & 0 & -0.54 & 0 & -0.83 & 5 & -1.41 & 43 & 1.7 \\
\hline 3 & 0 & -0.54 & 0 & -0.83 & 9 & 0.11 & 39 & 0.24 \\
\hline 4 & 1 & 1.38 & 3 & 2.96 & 17 & 3.15 & 27 & -4.15 \\
\hline 5 & 0 & -0.54 & 1 & 0.43 & 12 & 1.25 & 35 & -1.22 \\
\hline 6 & 1 & 1.38 & 0 & -0.83 & 9 & 0.11 & 38 & -0.13 \\
\hline 7 & 0 & -0.54 & 0 & -0.83 & 2 & -2.56 & 46 & 2.8 \\
\hline 8 & 0 & -0.54 & 0 & -0.83 & 5 & -1.41 & 43 & 1.7 \\
\hline 9 & 0 & -0.54 & 0 & -0.83 & 2 & -2.56 & 46 & 2.8 \\
\hline 10 & 0 & -0.54 & 0 & -0.83 & 5 & -1.41 & 43 & 1.7 \\
\hline 11 & 0 & -0.54 & 2 & 1.7 & 15 & 2.39 & 31 & -2.69 \\
\hline 12 & 0 & -0.54 & 1 & 0.43 & 5 & -1.41 & 42 & 1.34 \\
\hline 13 & 0 & -0.54 & 0 & -0.83 & 6 & -1.03 & 42 & 1.34 \\
\hline 14 & 0 & -0.54 & 0 & -0.83 & 3 & -2.18 & 45 & 2.43 \\
\hline 15 & 1 & 1.38 & 0 & -0.83 & 14 & 2.01 & 33 & -1.95 \\
\hline 16 & 0 & -0.54 & 2 & 1.7 & 10 & 0.49 & 36 & -0.86 \\
\hline 17 & 0 & -0.54 & 0 & -0.83 & 14 & 2.01 & 34 & -1.59 \\
\hline 18 & 0 & -0.54 & 0 & -0.83 & 6 & -1.03 & 42 & 1.34 \\
\hline 19 & 0 & -0.54 & 0 & -0.83 & 6 & -1.03 & 42 & 1.34 \\
\hline 20 & 0 & -0.54 & 2 & 1.7 & 9 & 0.11 & 37 & -0.49 \\
\hline 21 & 0 & -0.54 & 0 & -0.83 & 5 & -1.41 & 43 & 1.7 \\
\hline 22 & 4 & 7.15 & 2 & 1.7 & 11 & 0.87 & 31 & -2.69 \\
\hline 23 & 1 & 1.38 & 0 & -0.83 & 17 & 3.15 & 30 & -3.05 \\
\hline 24 & 0 & -0.54 & 1 & 0.43 & 11 & 0.87 & 36 & -0.86 \\
\hline 25 & 0 & -0.54 & 0 & -0.83 & 1 & -2.94 & 47 & 3.17 \\
\hline 26 & 0 & -0.54 & 0 & -0.83 & 10 & 0.49 & 38 & -0.13 \\
\hline 27 & 0 & -0.54 & 0 & -0.83 & 10 & 0.49 & 38 & -0.13 \\
\hline 28 & 1 & 1.38 & 1 & 0.43 & 13 & 1.63 & 33 & -1.95 \\
\hline 29 & 0 & -0.54 & 0 & -0.83 & 10 & 0.49 & 38 & -0.13 \\
\hline 30 & 0 & -0.54 & 1 & 0.43 & 6 & -1.03 & 41 & 0.97 \\
\hline 31 & 0 & -0.54 & 2 & 1.7 & 14 & 2.01 & 32 & -2.32 \\
\hline 32 & 0 & -0.54 & 3 & 2.96 & 12 & 1.25 & 33 & -1.95 \\
\hline TOTAL & 9 & & 21 & & 279 & & 1,227 & \\
\hline
\end{tabular}


iconographic 3D video, classes in video streaming, videoconference, and case simulation. ${ }^{5}$ Supplementary literature was suggested to students and included government recommendations on treating leprosy patients, and relevant scientific articles.

After review in an education database (ERIC, www.eric.ed.gov) and in a medical database (PUBMED, www.pubmed.com), the authors failed to find any validated tool appropriate for this distance learning evaluation. The Web Site Motivational Analysis Checklist (WebMAC) was originally created to evaluate learning materials in the World Wide Web. Therefore, we made an adaptation of the validated instrument WebMAC Professional with the author's permission, ${ }^{7}$ making it applicable to evaluate distance courses. We maintained the essential information of each of the original questions, and the alterations were made in accordance with this strategy.

The WebMAC Professional contains 32 standardized questions that are grouped into four motivational dimensions predefined by developers' team: "STIMULATING," "MEANINGFUL," "ORGANIZED," and "EASY-TO-USE." It was employed to evaluate the educational proposals. According to WebMAC methodology, the course outcome was evaluated using Cartesian projection. ${ }^{7}$ The X axis (called "value") reflects the sum of scores obtained in "STIMULATING" and "MEANINGFUL" dimensions and the $\mathrm{Y}$ axis (called "expectation for success") reflects the sum of scores obtained in "ORGANIZED" and "EASY-TO-USE."

At the end of the course, participants answered anonymously and spontaneously the questionnaire presented in Table 1, whereby a professional stratification of performance was not performed.

The criterion for course approval was an overall frequency of 70\% in all activities as chats, discussion lists, videostreaming, videoconferencing, and a case simulator.

Participants were guided to access all learning objects, and each entrance was computed with the aim to register their frequency to achieve course approval criteria.

Statistical analysis was carried out by Biostat 4.0 (Sociedade Civil Mamirauá, Belém, PA) ${ }^{8}$ and SPSS 15.0 (SPSS Inc., Chicago, IL). ${ }^{9}$ Cronbach's alpha was chosen to assess the internal consistency of the questionnaire. ${ }^{10}$ The $\chi 2$ test was used to check differences on the performance in each of the dimensions. ${ }^{11}$ Answers were classified as "positive" or "negative" based on agreement or disagreement, respectively. After that, residual and correspondence analysis were used to evaluate them. ${ }^{11}$
Statistical significance was accepted at $p<0.05$ (two-tail).

\section{Results}

The course was directed toward FHT's healthcare professionals working in the cities of Manaus and Parintins, which were located in the Legal Amazon during the period September 12 and October 24, 2007. Forty-eight participants answered the evaluation's questionnaire. The number of hours estimated for the course was 30 hours.

Cronbach's alpha from the adapted WebMAC was 0.79, suggesting adequate internal consistency ( $>0.7)$.

Table 2 shows the frequencies of answers obtained by each question. Questions with significant differences disclosed by residual analysis were highlighted.

The frequencies of answers grouped by motivational dimensions are in Figure 1. More than 95\% of them were considered "positive" ("somewhat agree" or "strongly agree"). The $\chi 2$ test demonstrates significant differences between dimensions ( $p<0.01)$. Two significant differences were identified using residual analysis. The dimension "STIMULATING" had a better performance $(p<0.01)$,

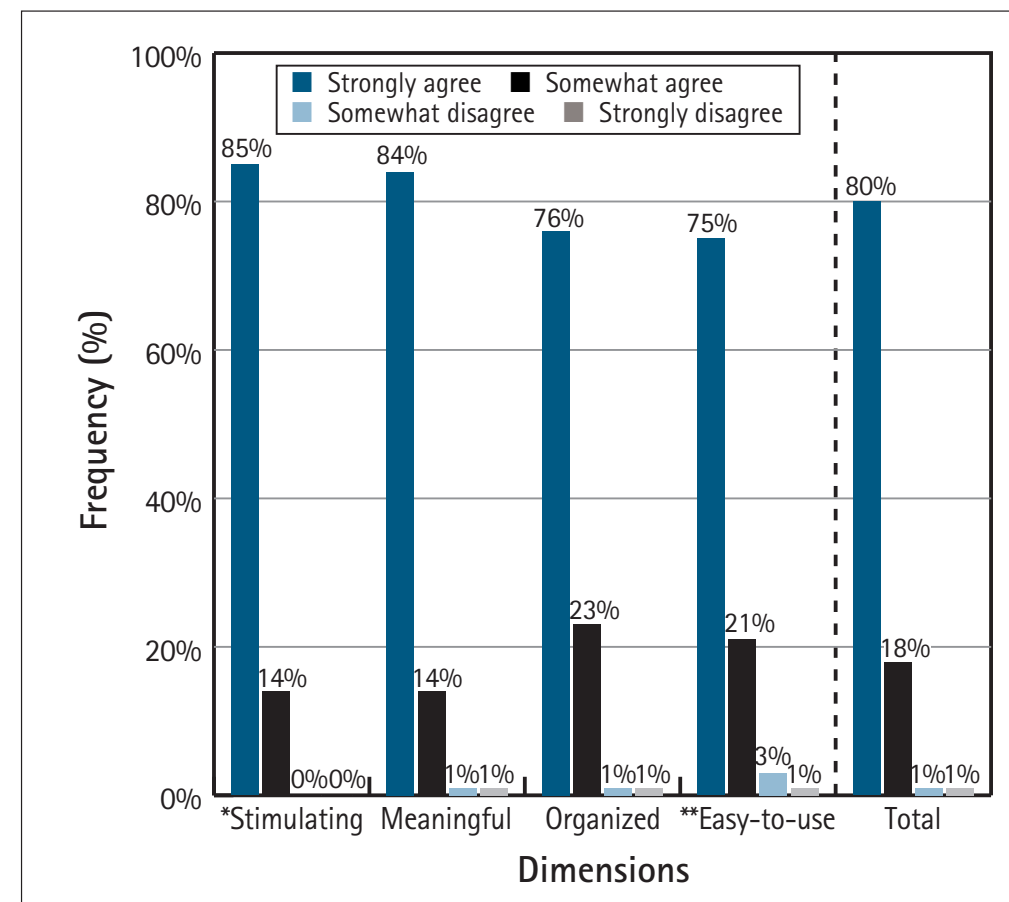

* Dimension with positive evaluation with statistical difference $(p<0.05)$ using residual analysis.

** Dimension with negative evaluation with statistical difference $(p<0.05)$ using residual analysis.

Fig. 1. Frequency distribution of the answers grouped by each motivational dimension $(N=48)$. 
based on the number of "positive" evaluations, and the dimension "EASY-TO-USE" received a more significant number of evaluations as "negative" ("somewhat disagree" or "strongly disagree").

Figure 2 displays the correspondence analysis among the motivational dimensions and participant agreement. The chart shows that the four dimensions are grouped near "somewhat agree" and "strongly agree" plotted in an abstract space.

The comments, made on the open part of the questionnaire, were also grouped and are listed in Table 3.

According to the classification's criteria used in the WebMAC, 47 (98\%) participants evaluated the course as “Awesome Course!”.

In Figure 3, using the WebMAC methodology, the $\mathrm{X}$ axis (called "value") reflects the sum of scores obtained in "STIMULATING" and "MEANINGFUL" dimensions. The Y axis (called "expectation for success") reflects the sum of scores obtained in "ORGANIZED" and "EASY-TO-USE." Point "A" was plotted based on median scores of each dimension, which were added in pairs. It determined the point coordinates and reflects global outcome. ${ }^{7}$

\section{Discussion}

Both the geographical situation of the Amazon and the diffuse-

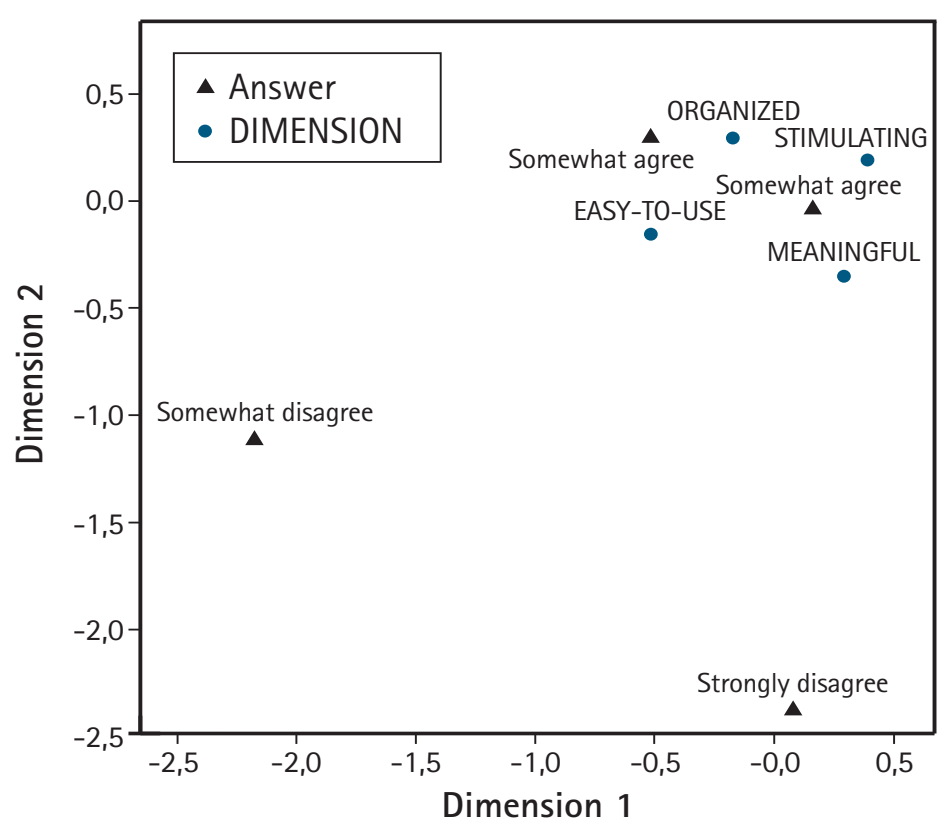

Fig. 2. Correspondence analysis of the dimensions based on the answers $(n=48)$. ness of leprosy's epidemic encourage the use of tele-education as a strategy for training FHT. ${ }^{12,13}$

The magnitude of the leprosy problem in the country, along with the educational needs demanded by the large increase in FHTs, favors the development of this tele-education's experience focused on disease diagnosis/suspicion. These factors could act together to limit leprosy transmission. ${ }^{14}$

It is essential to evaluate the potential uncertainties brought about by this initiative. A pedagogic assessment of this learning tool could reveal fundamental information. ${ }^{15}$

There are actually numerous tools to assess the utility of online courses and how much people actually learn. However, it is also important that even with the right concept, people still need motivation to pursue the course properly. This is clearly observed during campaigns against drug abuse and smoking cessation.

WebMAC was designed for professional educators to assess information used for education on the Web. It evaluates the "motivational quality." For example, a Web site with high motivational quality contains those features that motivate customers to visit, explore, and return to it.

Internal consistency is the extent to which tests or procedures assess the same characteristic, skill, or quality. It is a measure of homogeneity among observers in a study. Cronbach's alpha demonstrated the suitable internal consistency of the adapted instrument. This finding is a prerequisite for constructs execution. This encourages future work in order to pursue its external validation.

There was a high rate of satisfaction $(80 \%$ of the answers referred as "strongly agree"). Residual analysis showed the main positive points. The clarity in the proposal of the course, the opportunity for interaction, the updated information, the stimulus to search the content, the facility of navigation, the orientations during the use of resources (discussion list, chat, video), the accessibility of the offered resources, the motivational stimulation, the existence of relevant information on the topics, and lack of errors in the content of the course were mentioned. These fundamentals should be highlighted in future courses.

In contrast, the negative aspects, represented by "somewhat disagree" and "strongly disagree," were minor (less than 13\% in the worst performance question). The existence of redundant or unimportant information was cited. This can be explained by the option to provide basic information for all professionals, graduate level or not. Although the course was self-paced, videoconferenc- 


\begin{tabular}{|c|c|c|}
\hline COMPLIMENTS & FREQUENCY & $\%$ \\
\hline Opportunity to learn and review concepts & 36 & $75 \%$ \\
\hline Development of computer skills & 9 & $19 \%$ \\
\hline Good educational proposal & 1 & $2 \%$ \\
\hline Organization of the course & 1 & $2 \%$ \\
\hline Curricular importance & 1 & $2 \%$ \\
\hline Total & 48 & $100 \%$ \\
\hline SUGGESTIONS & FREQUENCY & $\%$ \\
\hline New tele-educational courses & 12 & $63 \%$ \\
\hline Improvement in the video quality & 1 & $5 \%$ \\
\hline $\begin{array}{l}\text { Increase in participation number and in number } \\
\text { of cities }\end{array}$ & 1 & $5 \%$ \\
\hline Improvement in access icons & 1 & $5 \%$ \\
\hline Permanent content access even after the course & 1 & $5 \%$ \\
\hline Videoconferences availability even after the event & 1 & $5 \%$ \\
\hline Paper version of the course & 1 & $5 \%$ \\
\hline Photos of physiotherapeutic treatment & 1 & $5 \%$ \\
\hline Total & 19 & $100 \%$ \\
\hline
\end{tabular}

ing (synchronous interaction) was done weekly to give instructions in how to use resources because participants requested more time for training before the use of resources. These points should be strengthened in the future.

The dimension of greatest positive performance was: "STIMULATING." It confirmed the impressions mentioned during interactive participation (chat and discussion list). The dimensions "MEANINGFUL" and "ORGANIZED" had a similar performance, and the low rate of negative assessments suggests that the course achieved its objective in these dimensions. In the dimension "EASY-TO-USE," the lowest performance demonstrated by residual analysis can be explained by the fact that this course is the first tele-educational experience for some FHT professionals. Nevertheless, the number of negative assessments was less than $5 \%$ of the total obtained in this dimension.

Regarding the disposition of the dimensions related to the answers obtained, all dimensions are grouped close to the answers considered positive. Therefore, in Figure 2, this analysis allows observation of the condensation of the dimension near the answers of positive evaluation, which demonstrated the global performance obtained for these dimensions.

The questionnaire's comments field was filled spontaneously, and confirmed points already identified by this new instrument, as well as others not recognized. Many compliments cited the opportunity to learn and review concepts (75\%) and the development of computer skills (19\%). In addition, students reported that the course offered a great opportunity to learn about leprosy, reinforcing the intent to offer basic information to everyone, despite the comments made by a minority about the course redundancy. Moreover, it confirmed that many of them had no experience with computers, and it could explain what happened in the dimension "EASY-TO-USE." Among the suggestions, the development of new courses (63\%) was emphasized, supporting the good acceptance of the method.

Together, these data show the quality of the course in the studied population. Forty-seven (98\%) of the participants said that the course was an "awesome course!". This encourages the authors to move forward in this research line, including future evaluations using the adapted WebMAC. The negative points and suggestions are challenges inherent in educational projects that should be constantly improved. A constructivist learning model recognizes the unique needs and backgrounds of each learner. It emphasizes the importance of the learner being actively involved in

Fig. 3. Classification criterion based on WebMAC Professional. Average to high
for value/Below average
to low for expectation
for success 
the learning process, constructing their own understanding. Moreover, the use of interactive learning objects helps learners to improve their own skills. Thus, this purpose in the course encouraged an interactive and participatory component throughout the learning process. ${ }^{16}$

Andragogy consists of learning strategies focused on adults. This theory has differences from traditional pedagogy, which is usually found in conventional schools. Problem-centered learning, learning subjects that have immediate relevance to a professional job, learning activities to provide experience to the participants of the course, and the involvement of the participants in the planning and evaluation for their instruction are postulates of andragogy. ${ }^{17}$ These fundamentals, used in this course, were considered a really important approach for this kind of public.

The motivation scores shown by this analysis were very favorable to the adopted model. A well-developed educational proposal, with the support of an experienced and motivated team comprised of teachers and coordinators, promotes success. There is a risk involved with the provision of mass education using tele-education without proper pedagogical concern. In this circumstance, a superficial analysis, lacking the absence of clear pedagogic objectives, causes a misinterpretation, transferring culpability to a wrong element, and implicating, for example, the nonpresence modality as the reason for failure. Therefore, a well-conducted educational evaluation should be encouraged for diagnosis purposes.

The tele-education on leprosy consolidated as a university extension course had an appropriate educational proposal, seeking good-quality education and allowing constant professional updating. It explained the importance of diagnostic evaluation, mainly because it is a pioneering experience, to identify the overall satisfaction of those involved, as well as items that could be improved in new courses. Therefore, the authors hope to improve future Web-based courses, learning from their experiences with the leprosy course and taking into account the many suggestions they received from their students.

This analysis showed that the WebMAC could be used to evaluate a Web-based course, and it was sustained by the questionnaire data. Furthermore, WebMAC was also used in other educational proposals. ${ }^{18-21}$ Even after an extensive review, authors could not find any other instrument with the purpose to evaluate motivational aspects. Nevertheless, before the unrestricted use of any validated instrument, it is important to recognize the limitations arising from the specificity of the system. Finally, it seems possible that there is not a unique and perfect instrument to evaluate all distance courses. Complexity involved with the education process and its different purposes help to explain this absence.

The expansion of the FHTs, the creation of the National Telehealth Program, the expansion and improvement of digi- tal communication infrastructure with the Brazilian University Telemedicine Network Project (including national institutions and universities), and the growing use of well-planned distance courses demand an attractive scenario for health tele-education initiatives. Educational planning is crucial for the sustainability of these initiatives.

\section{Acknowledgments}

We would like to thank the collective and participative spirit of course participants; the support of colleagues Dr. Luiz Jorge Fagundes, Dra. Maria Angela Trindade, Dr. Cyro Festa Neto, and Dr. Cleinaldo de Almeida Costa; Dr. Francisco Tussolini, Municipal Health Secretary of Parintins, for his belief in the objectives of the course; and to Marcelo Minoru Onoda, technical support coordinator at Discipline of Telemedicine at Sao Paulo University's School of Medicine. Moreover, the authors are thankful to the reviewers for their significant contributions to this article.

\section{Disclosure Statement}

No competing financial interests exist.

\section{REFERENCES}

1. Martelli CMT, Stefani MMA, Penna GO, Andrade ASS. Brazilian endemisms and epidemics, challenges and prospects for scientific investigation: Leprosy [in Portuguese]. Rev Bras Epidemiol 2002;5:273-284.

2. Magalhães MCC, Rojas LI. Spatial differentiation of leprosy in Brazil [in Portuguese]. Epidemiol Serv Saúde 2007;16:75-84.

3. Department of Primary Care of Brazil's Health Ministry. Atenção Básica e Saúde da Familia [in Portuguese]. Available at: http://dtr2004.saude.gov.br/dab/atencaobasica.php (Last accessed August 20, 2008).

4. Martins JG, Oliveira CM, Cassol MP, Spanhol FJ. Using online interfaces in the evaluation of distance courses in higher education. In: Silva M, Santos EO, eds. Evaluation of learning in online education [in Portuguese]. São Paulo, SP: Loyola, 2006:485-495.

5. Paixão MP, Miot HA, de Souza PE, Haddad AE, Wen CL. A university extension course in leprosy: Telemedicine in the Amazon for primary healthcare. $J$ Telemed Telecare 2009;15:64-67.

6. Wen CL, Silveira PS, Azevedo RS, Böhm GM. Internet discussion lists as an educational tool. J Telemed Telecare 2000;6:302-304.

7. Small RV, Arnone MP. The Website Motivational Analysis Checklist (WebMAC): Professional. Available at: http://digital-literacy.syr.edu/resources/WebMac.htm (Last accessed August 28, 2008).

8. Ayres M, Ayres M Jr, Ayres DL, Santos AS. BioEstat 4.0-Statistical applications in the areas of biological and medical sciences [in Portuguese]. Belém, PA: Sociedade Civil Mamirauá, 2005

9. SPSS Incorporation. SPSS 15.0 for Windows. Statistical Package for Social Science Release Version 15.0.1. Chicago, IL: SPSS Inc., 2006. 


\section{TELE-EDUCATION ON LEPROSY}

10. Pereira JCR. Analysis of qualitative data [in Portuguese]. São Paulo, SP: Edusp, 2004

11. Kirkwood BR, Sterne JAC. Essential medical statistics. Malden, MA: Blackwell Publishing, 2003.

12. Miot HA, Paixão MP, Wen CL. Teledermatology: Past, present and future [in Portuguese]. An Bras Dermatol 2005;80:523-532.

13. Chao LW, Silveira PS, Böhm GM. Telemedicine and education in Brazil. J Telemed Telecare 1999;5:137-138.

14. Britton WJ, Lockwood DN. Leprosy. Lancet 2004;363:1209-1219.

15. Huang W, Huang W, Diefes-Dux $H$, et al. A preliminary validation of Attention, Relevance, Confidence and Satisfaction model-based Instructional Material Motivational Survey in a computer-based tutorial setting. Br J Educ Technol 2006;37:243-259.

16. Primo A. Evaluation of processes in problematizing online education. In: Silva M, Santos EO, eds. Evaluation of processes in problematizing online education [in Portuguese]. São Paulo, SP: Loyola, 2006:37-49.

17. Knowles MS. The modern practice of adult education: Andragogy versus pedagogy. New York: Association Press, 1970.

18. Paim RL, Azevedo FM, Koerich GM, Dulfloth RM, Vieiria DSC, Malinverni MS. Interface with adaptive hypermedia system in breast cancer using artificial neural networks MLP and IAC. In: Brazilian Congress of Informatics in Health$\mathrm{BCIH}$. Florianopolis, SC: Brazilian Congress of Informatics in Health-BCIH [in Portuguese]. 2006.
19. Malinverni MS, Azevedo FM, Koerich GM, Paim RL, Vieiria DSC, Dulfloth RM. Hypermedia system in cervical cancer with adaptive interface. In: XX Brazilian Congress of Biomedical Engineering [in Portuguese]. São Pedro, SP: XX Congress of Biomedical Engineering, 2006.

20. Small RV, Arnone MP. Motivation mining: Prospecting the Web. Book Report 1999;18:42-44.

21. Small RV, Arnone MP. Evaluating the motivational effectiveness of children's Websites. Educ Technol 1999;39:51-55.

Address correspondence to: Maurício Pedreira Paixão, M.D., Ph.D. Faculdade de Medicina da Universidade de São Paulo Av. Dr. Arnaldo, 455, sala 2103 Sao Paulo SP 01246-903 Brazil

E-mail: mauricio@telemedicina.fm.usp.br

Received: October 1, 2008 Accepted: December 3, 2008 
This article has been cited by:

1. Arnaud Belard, Derek Dolney, Tochner Zelig, James McDonough, John O'Connell. 2011. Improving Proton Therapy Accessibility Through Seamless Electronic Integration of Remote Treatment Planning Sites. Telemedicine and e-Health 17:5, 370-375. [Abstract] [Full Text HTML] [Full Text PDF] [Full Text PDF with Links] 